\title{
Inflammatory bowel disease with cytoplasmic-staining antineutrophil cytoplasmic antibody and extensive colitis
}

Hugh James Freeman MD

HJ Freeman. Inflammatory bowel disease with cytoplasmicstaining antineutrophil cytoplasmic antibody and extensive colitis. Can J Gastroenterol 1998;12(4):279-282. A cohort of 18 patients with inflammatory bowel disease who were characterized by the presence of cytoplasmic-staining antineutrophil cytoplasmic antibody (cANCA) and extensive colitis is reported. Almost half were Indo-Canadians, and atypical perinuclear-staining antineutrophil cytoplasmic antibody was also detected in five (28\%), similar to the detection rate for Crohn's disease and other less commonly detected forms of colitis, such as lymphocytic or collagenous colitis. Careful pathological review of all endoscopic biopsies and surgically resected colonic tissues did not reveal evidence of vasculitis or so-called 'palisading' granulomas, which is a typical pathological change of Wegener's granulomatosis, an entity that has been traditionally characterized by the detection of cANCA. This report describes 18 patients with extensive colitis and the seromarker cANCA but without clinical features or histological evidence of vasculitis.

Key Words: Antineutrophil cytoplasmic antibodies, Crohn's disease, Granulocytes, Inflammatory bowel disease, Ulcerative colitis

\section{Maladie inflammatoire de l'intestin avec anticorps cytoplasmiques antineutrophiles colorant le cytoplasme et colite étendue}

\begin{abstract}
RÉSUMÉ : Le présent rapport porte sur une cohorte de 18 patients atteints de maladie inflammatoire de l'intestin caractérisée par la présence d'anticorps cytoplasmiques antineutrophiles (cANCA) colorant le cytoplasme et une colite étendue. Près de la moitié des sujets étaient des Indo-Canadiens, et on a également décelé chez cinq d'entre eux $(28 \%)$ un anticorps cytoplasmique antineutrophile à coloration périnucléaire atypique, ce qui correspond au taux de dépistage observé dans la maladie de Crohn et d'autres formes plus rares de colite, comme la colite lymphocytaire ou collagénique. L'examen pathologique attentif de toutes les biopsies endoscopiques et des tissus réséqués chirurgicalement n'a révélé aucun signe de vasculite ou de granulomes palissadiques, signes caractéristiques de la granulomatose de Wegener, maladie habituellement confirmée par le dosage des cANCA. Ce rapport décrit 18 patients atteints de colite étendue présentant le marqueur sérologique cANCA, sans les caractéristiques cliniques ni les signes histologiques de vasculite.
\end{abstract}

A ntineutrophil cytoplasmic antibodies (ANCA) are a group of neutrophil antibodies traditionally defined by their reactivity on indirect immunofluorescent staining with alcohol fixed neutrophils; these antibodies have been used as a diagnostic aid in patients with necrotizing vasculitis, in particular, Wegener's granulomatosis $(1,2)$.

ANCA subclasses include a diffuse cytoplasmic staining pattern (cANCA) and a perinuclear staining pattern
(pANCA). In patients with vasculitis, the primary antigen specificity for cANCA is proteinase-3 (PR-3) and for pANCA is myeloperoxidase (MPO). Recently, a specific subclass of ANCA was also detected in most patients with idiopathic ulcerative colitis but in a minority of patients with Crohn's disease (3-6). This atypical pANCA in patients with inflammatory bowel disease (IBD) has a perinuclear staining pattern but does not react with MPO.

Department of Medicine (Gastroenterology), University of British Columbia, Vancouver, British Columbia

Correspondence and reprints: Dr Hugh Freeman, ACU F-137, Gastroenterology, Vancouver Hospital (UBC site), 2211 Wesbrook Mall, Vancouver, British Columbia V6T 1W5. Telephone 604-822-7216, fax 604-822-7236

Received for publication March 1, 1998. Accepted March 17, 1998 


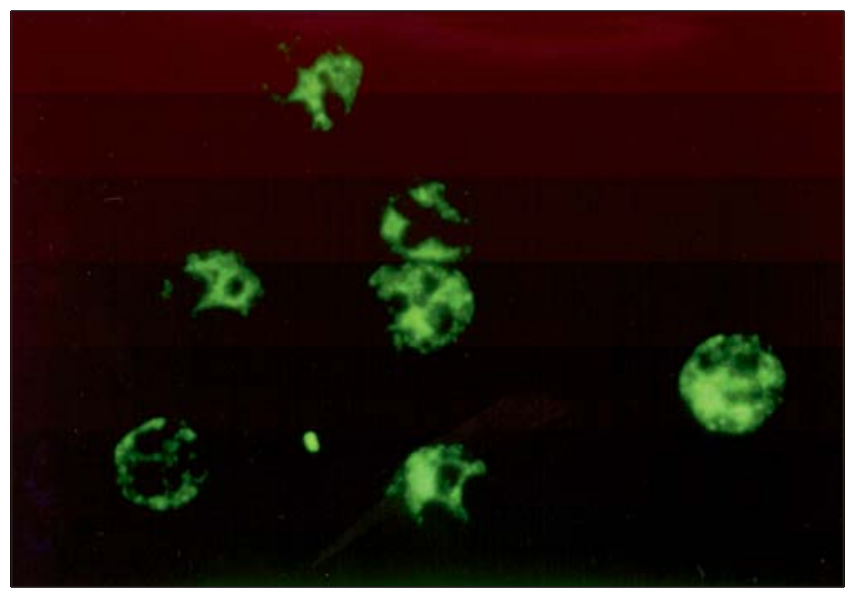

Figure 1) Cytoplasmic-staining antineutrophil cytoplasmic antibody pattern in a patient with extensive ulcerative colitis. In this patient, proteinase- 3 antibodies were positive

\section{TABLE 1}

Characteristics of seropositive (cytoplasmic-staining antineutrophil cytoplasmic antibody) colitis patients

\begin{tabular}{|c|c|c|c|}
\hline Age/sex & Country & Antibodies & Extent of colitis \\
\hline $51 / M$ & Tanzania* & 1:80; PR-3(-) & Extensive $>100 \mathrm{~cm}^{\ddagger}$ \\
\hline $16 / F$ & Canada* & $1: 320 ;$ PR-3(-) & Extensive $>60 \mathrm{~cm}$ \\
\hline $23 / \mathrm{F}$ & Canada & $1: 40 ;$ PR-3(-) ${ }^{\dagger}$ & Extensive $>80 \mathrm{~cm}$ \\
\hline $22 / M$ & Canada & $1: 40 ;$ PR-3(+) & Extensive $>100 \mathrm{~cm}^{\ddagger}$ \\
\hline $29 / F$ & Kenya* & $1: 320 ;$ PR-3(+) & Extensive $>60 \mathrm{~cm}^{\ddagger}$ \\
\hline $18 / M$ & Canada & $1: 160 ;$ PR-3(+) ${ }^{+}$ & Extensive $>60 \mathrm{~cm}$ \\
\hline $31 / F$ & India* & $1: 160 ;$ PR-3(-) & Extensive $>60 \mathrm{~cm}$ \\
\hline $43 / M$ & Uganda* & $1: 320 ;$ PR-3(+) ${ }^{+}$ & Extensive $>100 \mathrm{~cm}^{\ddagger}$ \\
\hline $43 / F$ & Canada & 1:20; PR-3(-) & Extensive $>100 \mathrm{~cm}^{\ddagger}$ \\
\hline $36 / F$ & Mexico & 1:80; PR-3(-) & Extensive $>100 \mathrm{~cm}^{\ddagger}$ \\
\hline $39 / M$ & Canada & $1: 40 ;$ PR-3(-) & Distal to $28 \mathrm{~cm}$ \\
\hline $34 / M$ & Canada & $1: 80 ;$ PR-3(+) & Extensive $>100 \mathrm{~cm}^{\ddagger}$ \\
\hline $20 / M$ & Canada & 1:40; PR-3(-) & Extensive $>60 \mathrm{~cm}$ \\
\hline $52 / F$ & Canada & $1: 20 ;$ PR-3(+) & Extensive $>100 \mathrm{~cm}^{\ddagger}$ \\
\hline $26 / F$ & Canada & $1: 160 ;$ PR-3(-) $)^{\dagger}$ & Extensive $>100 \mathrm{~cm}^{\ddagger}$ \\
\hline $37 / M$ & India* & $1: 320 ;$ PR-3(-) & Extensive $>60 \mathrm{~cm}$ \\
\hline $16 / F$ & Canada & $1: 20 ;$ PR-3(+) & Extensive $>100 \mathrm{~cm}^{\ddagger}$ \\
\hline $16 / M$ & India* & $1: 20 ;$ PR-3 $3(+)^{\dagger}$ & Extensive $>100 \mathrm{~cm}$ \\
\hline
\end{tabular}

*Indo-Canadians $(n=7)$ including three born in India, three born in East Africa but parents born in India and one born in Canada (parents from Fiji); ${ }^{+}$Seropositive for atypical perinuclear-staining antineutrophil cytoplasmic antibody and one also positive for myeloperoxidase (ie, 43/M); ${ }^{\ddagger}$ Extensive colitis with ulceration and inflammatory pseudopolyps. M Male; F Female

Recent studies have now detected a possible source for ANCA in mucosa-associated lymphoid tissue (7) but have not defined any particular correlation with the severity or extent of the colitis (5).

ANCAs are not present in patients with infectious forms of colitis (5) but are present after colectomy in patients with either ulcerative colitis or Crohn's disease (8). To date, most published studies in patients with IBD have focused on atypical pANCA and the possible relevance of this seromarker to diagnosis and management.

In on-going prospective studies in our centre of neutrophil antibodies in patients with different forms of IBD, over 1000 patients have now been evaluated for these seromarkers. During the course of these investigations, it was noted that an occasional, rare patient (ie, fewer than $2 \%$ of patients tested with inflammatory bowel disorders) had the cANCA staining pattern. Because this particular seromarker has been considered diagnostic of Wegener's granulomatosis, an unusual granulomatous disorder with a systemic necrotizing vasculitis $(9,10)$, the clinical and pathological features of these 18 patients with a positive cANCA immunofluorescent staining pattern were further examined. The results suggest an unusual and distinctive group of patients, many of Asian (ie, Indian) descent, with a clinically severe and a structurally extensive form of colitis, including inflammatory pseudopolyposis.

\section{PATIENTS AND METHODS}

Patients: A diagnosis of IBD was based on clinical, radiologic, endoscopic and histological criteria, as well as negative microbiological studies (11). For disease extent and site, previous established criteria for idiopathic ulcerative colitis were used (5). Distal colitis was defined if continuous mucosal inflammatory changes were localized to the most distal $60 \mathrm{~cm}$ of the colorectum, while extensive colitis was defined as continuous mucosal changes over $60 \mathrm{~cm}$. In a previously reported prospective study from our centre (5), $53 \%$ (or 131) of $247 \mathrm{ul}$ cerative colitis patients had distal colitis and $47 \%$ (or 116) had extensive disease. In the present report of 1000 patients with IBD studied to date, including an initial group of $500 \mathrm{pa}$ tients reported (5), 18 were detected with cANCA.

ANCA assays: Blood samples were collected into vacutainer glass tubes, allowed to clot at room temperature and used for detection of ANCA with two methods: ANCA immunofluorescence and ANCA ELISA. Serological studies for ANCA were done by a single laboratory technologist blinded to the clinical details and diagnosis as well as to the extent and severity of disease. Briefly, indirect ANCA immunofluorescence was performed with a standardized fluorescent antibody detection method $(12,13)$ using a proprietary kit (Inova Diagnostics, Inc, California). Figure 1 shows a positive cANCA result in a patient with extensive ulcerative colitis. If immunofluorescent staining was present for any ANCA subclass, ANCA ELISA was done for antibodies to a serine protease, $\mathrm{PR}-3$, and $\mathrm{MPO}$ using standardized methods $(12,13)$ with commercial kits (Quantalite PR3 and MPO ELISA, Inova Diagnostics, Inc). All patients were antinuclear antibody-negative and DNA antibody-negative.

\section{RESULTS}

Eighteen patients with IBD had cANCA detected, for an overall incidence in prospectively evaluated IBD patients of less than $2 \%$. Clinical features, country of birth, antibody status and extent and severity of the colitis in all 18 patients examined are outlined in Table 1. 
Clinical features: Patients comprised nine males and nine females, mean age 30.7 years (mean age 31.1 years for males, 30.2 years for females). Of the 18 patients, seven (38.9\%) were Indo-Canadians, mean age 31.9 years. Six of seven Indo-Canadians immigrated to Canada at least 10 years before the onset of clinical symptoms, either from India or an East African nation; one female of Indian descent was born in British Columbia. Except for one patient from Mexico, all others were born in Canada.

Table 2 lists the clinical symptoms including diarrhea, rectal bleeding and weight loss of more than $5 \mathrm{~kg}$. Other extra-intestinal features of colitis were not detected in any of the 18 patients. No patient exhibited clinical features of a necrotizing vasculitis, or disease in the respiratory or renal tracts. One patient had a history of a deep vein thrombosis treated in 1983 with coumadin.

The clinical symptoms in these 18 patients were generally associated with severe and extensive colonic inflammatory changes that were documented with endoscopic and histologic evaluations.

As shown in Table 2, most had features of extensive mucosal colonic disease (ie, over $60 \mathrm{~cm}$ ). Many had extensive mucosal ulceration with colonic inflammatory pseudopolyposis.

Steroid and/or immunosuppressants were required for most patients; some, to date, have also undergone a proctocolectomy with pelvic pouch (J type) reconstruction. In each of these 18 cANCA-positive patients, endoscopically obtained biopsies and surgically resected colon were all reviewed and showed no microscopic changes of vasculitis.

Antibody studies: All 18 patients were positive for cANCA by using a standardized immunofluorescent staining method. Of these, eight patients (44\%) were also positive for antibodies to PR-3, the putative antigen for cANCA in Wegener's granulomatosis $(9,10)$, and one patient also had an antibody against MPO, a target antigen for pANCA (14). Although all patients had distal colonic disease, usually with extensive mucosal involvement typical of idiopathic ulcerative colitis, only five of the 18 patients (28\%) had an atypical pANCA detected. This result of $28 \%$ contrasts with our previous result of $66.3 \%$, reported in 247 patients with idiopathic ulcerative colitis from our centre (5), and contrasts with results from others $(3,12,13)$, and seems to approximate closely the percentage of patients with atypical pANCA in other forms of colitis, eg, Crohn's disease with colitis alone $(18.9 \%)$ or lymphocytic and collagenous colitis with or without celiac disease $(16.3 \%)(5,15)$.

\section{DISCUSSION}

This report documents a cohort of 18 patients with clinical and endoscopic features characteristic of severe and extensive colitis coupled with serological detection of cANCA. Almost all patients had diarrhea, rectal bleeding and endoscopically defined extensive colitis, most often with inflammatory pseudopolyposis and a need for steroid treatment, proctocolectomy or both. Our present results contrast with the previously reported experience from our centre in a pro-
TABLE 2

Clinical features in 18 colitis patients

\begin{tabular}{lc}
\hline Feature & Total: number (\%) \\
\hline Diarrhea & $18(100)$ \\
Rectal bleeding & $16(89)$ \\
Weight loss $(>5 \mathrm{~kg})$ & $6(33)$ \\
Liver disease & $1(6)$ \\
Extra-intestinal features & $1(6)$ \\
Extensive disease $(>60 \mathrm{~cm})$ & $17(94)$ \\
Pseudopolyposis & $10(56)$ \\
Granulomas & $1(6)$ \\
Atypical pANCA & $5(28)$ \\
Steroid treatment & $17(94)$ \\
Colectomy and/or pelvic pouch & $3(17)$ \\
5-aminosalicylate sensitivity & $1(6)$ \\
Family history of colitis & $1(6)$ \\
\hline
\end{tabular}

pANCA Perinuclear-staining antineutrophil cytoplasmic antibody

spectively evaluated group of 247 patients with idiopathic ulcerative colitis (5) where extensive colitis was defined in fewer than $50 \%$. Interestingly, a significant number of patients in the present report were Indo-Canadians; however, it would be premature to suggest an ethnic basis for the observations in the present study.

This entity of extensive colitis coupled with serological detection of cANCA is, in our experience, very uncommon. Although rare cases with cANCA (15) or PR-3 antibodies (16) have previously been described, this is the first report to define prospectively the detection rate in a large series of IBD patients. More specifically, cANCA was detected in fewer than $2 \%$ of 1000 patients studied. Some of these patients also had atypical pANCA - a feature more characteristically seen in idiopathic ulcerative colitis - detected in serological studies, but the frequency in the present patient group was far less than that reported in earlier studies from our centre and by other investigators $(3,5,12,13)$. Together, these findings suggest a relatively distinctive entity, with more severe clinical features as well as extensive colonic structural changes, including ulceration and marked inflammatory pseudopolyposis. Alternatively, detection of this antibody in some of our patients may simply reflect the heterogeneous nature of this intriguing inflammatory colonic mucosal process.

In this study, antibodies to specific antigens were not uniformly seen in every patient. In patients with necrotizing forms of vasculitis, such as Wegener's granulomatosis $(9,10)$, the putative antigen is thought to virtually always be a $29 \mathrm{kDa}$ serine protease, PR-3, with elastinolytic and other functional properties $(9,10)$. PR-3 is present within neutrophil azurophilic granules and monocyte lysosomes. Some patients in the present study had antibodies to serine PR-3 but others did not. In contrast, pANCAs (distinct from atypical pANCA found in ulcerative colitis) are commonly, but not 
exclusively, directed against MPO, particularly in the setting of vasculitis and glomerulonephritis (14). This antibody was detected in one patient with cANCA, but not pANCA, using immunofluorescent staining. Most importantly, none of the patients reported in this study had clinical or pathological evidence of a necrotizing vasculitis or renal disease, including glomerulonephritis. Thus, cANCA in IBD patients may differ from the cANCA found in the systemic forms of necrotizing vasculitis, possibly even representing an 'atypical' cANCA, analogous to the 'atypical' pANCA reported in most patients with ulcerative colitis.

Interestingly, pathological evidence of gastrointestinal tract involvement in Wegener's granulomatosis has been previously reported, although the course of the disease was usually dominated by the characteristic necrotizing granulomatous lesions in the upper and lower respiratory tracts, along with vasculitis and glomerulonephritis. To date, fewer than 100 cases have been described with gastrointestinal involvement, usually with the characteristic vasculitic pathological features of Wegener's granulomatosis, the so-called

\section{REFERENCES}

1. Gross WL, Schmitt WH, Csernok E. ANCA and associated diseases: immunodiagnostic and pathogenetic aspects. Clin Exp Immunol 1993;91:1-12.

2. Hagen EC, Ballieux EPB, van Es LA, Daha MR, van der Woude FJ. Antineutrophil cytoplasmic antibodies: a review of the antigens involved, the assays, and the clinical and possible pathogenetic consequences. Blood 1993;81:1996-2002.

3. Saxon A, Shanahan F, Landers C, Ganz T, Targan S. A subset of antineutrophil anticytoplasmic antibodies is associated with inflammatory bowel disease. J Allergy Clin Immunol 1990;86:202-10.

4. Shanahan F, Landers C, Duerr R, Targan SR. Neutrophil autoantibodies as disease markers for ulcerative colitis. Immunol Res 1991;10:479-84.

5. Freeman H, Roeck B, Devine D, Carter C. Prospective evaluation of neutrophil autoantibodies in 500 consecutive patients with inflammatory bowel disease. Can J Gastroenterol 1997;11:203-7.

6. Freeman HJ. Atypical perinuclear antineutrophil cytoplasmic antibodies in patients with Crohn's disease. Can J Gastroenterol 1997;11:689-93.

7. Targan SR, Landers CJ, Cobb L, MacDermott RP, Vidrich A. Perinuclear anti-neutrophil cytoplasmic antibodies are spontaneously produced by mucosal B cells of ulcerative colitis patients. J Immunol 1995; $155: 3262-7$.

8. Freeman HJ, Roeck B, Devine DV, Carter CJ. Atypical perinuclear antineutrophil cytoplasmic antibodies after colectomy in inflammatory bowel disease. Can J Gastroenterol 1997;11:305-10.

9. Goldschmeding R, van der Schoot CE, ten Bokkel Huinink D, et al. Wegener's granulomatosis autoantibodies identify a novel diisopropylfluorophosphate-binding protein in the lysosomes of normal human neutrophils. J Clin Invest 1989;84:1577-87.

10. Ludemann J, Utecht B, Gross WL. Anti-neutrophil cytoplasm antibodies in Wegener's granulomatosis recognize an elastinolytic enzyme. J Exp Med 1990;171:357-62.

11. Lennard-Jones JE. Classification of inflammatory bowel disease. Scand J Gastroenterol 1989;24(Suppl 170):2-6.

12. Duerr RH, Targan SR, Landers CJ, Sutherland LR, Shanahan F. Neutrophil autoantibodies in ulcerative colitis. Comparison with other colitides/diarrheal diseases. Gastroenterology 1991;100:1590-6.

13. Duerr RH, Targan SR, Landers CJ, et al. Neutrophil cytoplasmic palisading granuloma centred on small arteries and veins with fibrinoid necrosis (17-24). Wegener's granulomatosis may also mimic the changes in IBD and is often considered in the differential diagnosis of patients with colitis (25).

\section{CONCLUSIONS}

A patient cohort with severe and extensive colitis associated with cANCA in the absence of any clinical or pathological changes of systemic or localized vasculitis was described. This association of colitis with serological detection of cANCA is rare, occurring in this series of 1000 prospectively studied patients with IBD in fewer than $2 \%$; its apparent increased propensity for Indo-Canadians with extensive colitis is intriguing. The findings in these 18 patients with colitis in the absence of small intestinal disease also seem to differ from a recently described case report (26) of cANCApositive vasculitis in colitis complicated by a small bowel infarction. Further studies will be needed to determine the relevance and specifically of this particular antibody in patients with IBD.

autoantibodies: a link between primary sclerosing cholangitis and ulcerative colitis. Gastroenterology 1991;100:1385-91.

14. Shanahan F. IBD-associated ANCA - current status. In: McLeod RS, Martin F, Sutherland LR, Wallace JL, Williams CN, eds. Trends in Inflammatory Bowel Disease Therapy 1996. Dordrecht: Kluwer Academic Publishers, 1997:14-20.

15. Li PK, Leung JC, Lai FM, et al. Use of antineutrophil cytoplasmic autoantibodies in diagnosing vasculitis in a Chinese patient population. Am J Nephrol 1994;14:99-105.

16. Rump JA, Scholmerich J, Gross V, et al. A new type of perinuclear antineutrophil antibody ( $\mathrm{p}$-ANCA) in active ulcerative colitis but not in Crohn's disease. Immunobiology 1990;181:406-13.

17. Freeman HJ. Perinuclear antineutrophil cytoplasmic antibodies in collagenous or lymphocytic colitis with or without celiac disease. Can J Gastroenterol 1997;11:417-20.

18. Fahey JL, Leonard E, Churg J, Godman C. Wegener's granulomatosis. Am J Med 1954;17:168-79.

19. Godman GC, Churg J. Wegener's granulomatosis (pathology and review of the literature). Arch Pathol 1954;58:533-53.

20. O'Duffy JD, Scherbel AL, Reldbord HE, McCormick LJ. Necrotizing angiitis I. A clinical review of twenty-seven autopsied cases. Cleve Clin Q 1965;32:87-98.

21. Reidbord HE, McCormick LJ, O'Duffy JD. Necrotizing angiitis II. Findings at autopsy in twenty-seven cases. Cleve Clin $Q$ 1965;32:191-204.

22. Carrington CB, Liebon AA. Limited forms of angiitis and granulomatosis of Wegener's type. Am J Med 1966;41:497-527.

23. Fauci AS, Wolff SM. Wegener's granulomatosis. Medicine 1973;52:535-61.

24. Kishikawa H, Watanabe T, Tanaka K. Wegener's granulomatosis-report of nine autopsy cases and review of the literature. Fukuoka Igaku Zasshi 1975;66:199-213.

25. Sokol RJ, Farrell MK, McAdams AJ. An unusual presentation of Wegener's granulomatosis mimicking inflammatory bowel disease. Gastroenterology 1984;87:426-32.

26. Weir A, Taylor-Robinson SD, Poole S, Pignatelli M, Walters JFR, Calam J. Cytoplasmic antineutrophil cytoplasmic antibody-positive vasculitis associated with ulcerative colitis. Am J Gastroenterology 1997;92:506-8. 


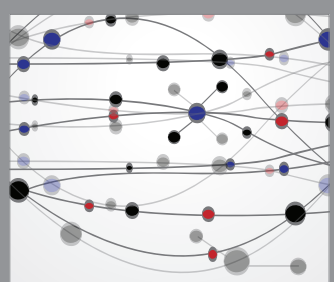

The Scientific World Journal
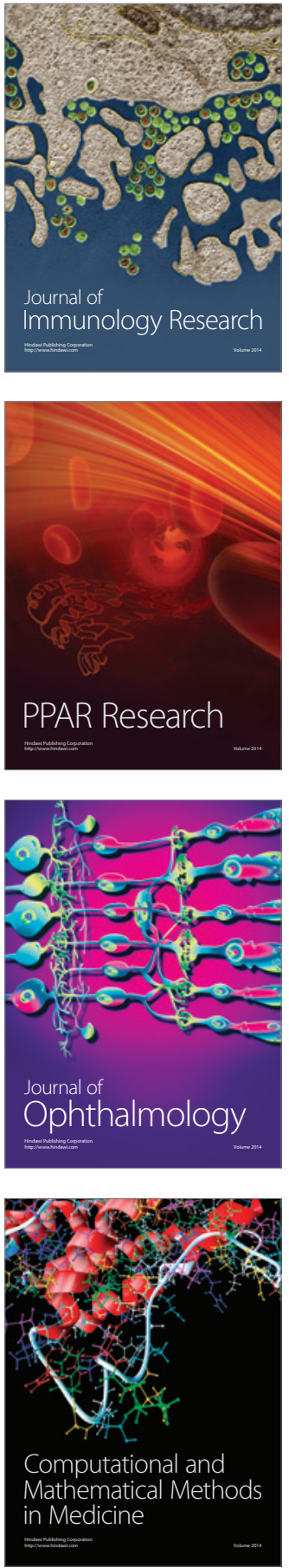

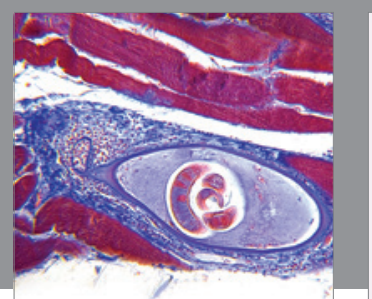

Gastroenterology Research and Practice

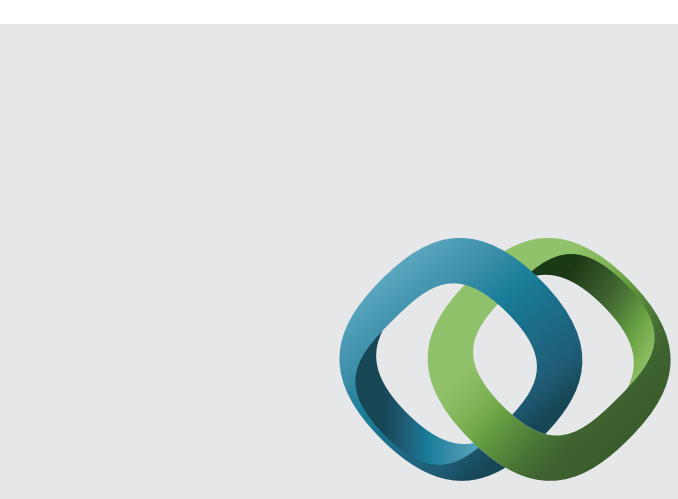

\section{Hindawi}

Submit your manuscripts at

http://www.hindawi.com
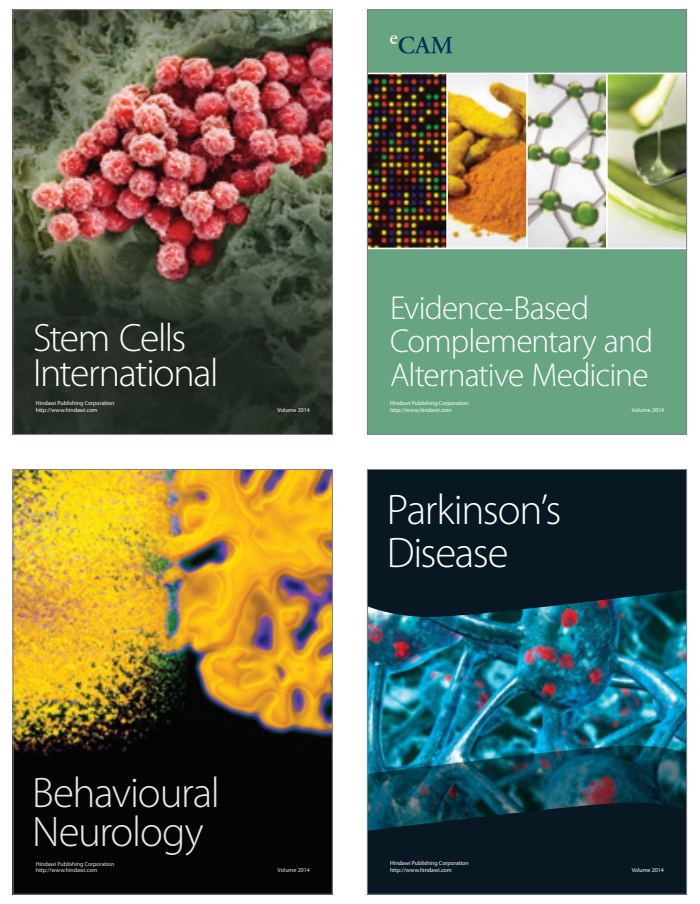
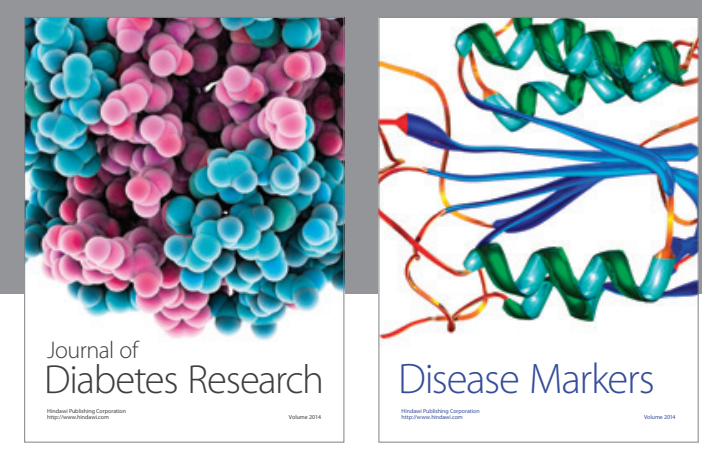

Disease Markers
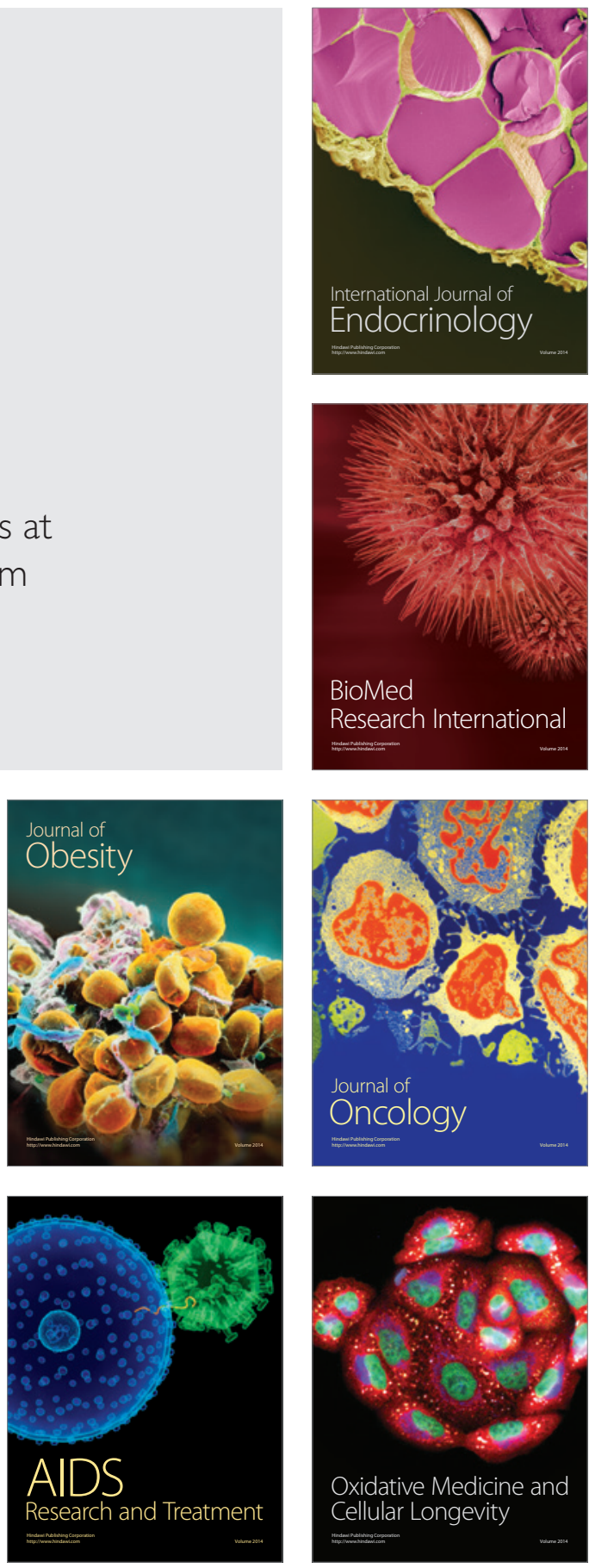